\title{
A tessitura continuada da intriga na narrativa seriada de televisão: uma proposta de análise da serialidade televisiva de longo prazo a partir de Breaking Bad,
}

\begin{abstract}
João Araújo ${ }^{1}$
Resumo: Neste artigo, sugerimos um proto-modelo para a observação das narrativas continuadas de longo prazo em ficções seriadas televisivas, desenvolvido a partir dos conceitos de fio, trama e tecido narrativos e do esquema actancial de Greimas, e ilustrado por meio de uma análise de Breaking Bad. Enfim, após a apresentação do modelo proposto, observamos ainda algumas das suas limitações, bem como alguns ganhos que ele proporciona, nomeadamente no que diz respeito à observação da modulação das temporadas, da economia e ritmo narrativos e da convocação imersiva.

Palavras-chave: Ficção seriada televisiva; serialidade; Greimas; estrutura narrativa; Breaking Bad.

Abstract: In this paper, we advance a proto-model for the observation of the long-term narratives in serialized television fictions, developed from the concepts of narrative thread, braid, and fabric and from Greimas' actantial model, and illustrated through an analysis of Breaking Bad. Finally, after presenting the proposed model, we also observe some of its limitations, as well assome of its advantages, namely concerning the flow of seasons, the narrative economy and rhythm and the convocation of spectatorial immersion. Keywords: Television series; serial narratives; Greimas; narrative structure; Breaking Bad.
\end{abstract}

\section{Introdução}

Desde os anos 1970, certas mudanças operadas no mercado televisivo estadunidense levaram a uma diversificação dos modelos de serialidade engajados pela mídia, e a velha dicotomia entre produtos episódicos iterativos (series) e altamente continuados (serials) passou progressivamente a se mostrar datada para os estudiosos do tema. Nesse sentido, ainda nos anos 1980, alguns trabalhos europeus pioneiros no tratamento formal da televisão já começaram a

${ }^{1}$ Bolsista de doutorado Capes pelo Programa de Pós-Graduação em Comunicação e Cultura Contemporâneas da Universidade Federal da Bahia. E-mail: jesilvaraujo@gmail.com. 
pensar a serialidade televisiva para além deste binarismo. Assim, por problemáticos que sejam os modelos de Vilches (1984), Eco ([1985] 1989) e Calabrese ([1987] 1999), em suas tipologias exaustivas estes autores já abandonavam a simplicidade do binarismo anterior, ainda que suas abordagens seguissem criando castas fixas para segmentar os produtos ficcionais, ignorando as inúmeras nuances e forçando as obras a se adequarem a categorias prédeterminadas.

Mais tarde, investidas teóricas mais sensíveis a variações específicas nos modelos de serialidade foram tomando forma. Allrath, Gymnich e Surkamp (2005), por exemplo, propõem pensar series/serials não como designadores rígidos, mas a partir de um continuum no qual produtos distintos se aproximam mais de uma ponta ou de outra. Assim, The Simpsons estaria próxima dos antigos serials, enquanto as soap operas seriam as narrativas mais continuadas, com várias outras obras em posições intermediárias. Todavia, mesmo superando a abordagem classificatória anterior, este modelo ainda peca ao não perceber que “o drama seriado contemporâneo não está em nenhum ponto desse continuum, mas em uma linha paralela que é, precisamente, o ponto abstrato em que os dois extremos desse continuumse encontram" (BARRETO, 2014, p. 2).

Esse drama contemporâneo de que estamos falando ao mesmo tempo supera e unifica as experiências episódicas e folhetinescas, numa síntese complexa de estruturas dramáticas que retém em si e deixam escapar tanto a unidade concisa da trama episódica, centrada na emissão única, quanto a expansão da trama pela temporada para um deleite irresoluto. Ao não fazer nem uma coisa nem outra, o drama seriado contemporâneo faz as duas, escrevendo a sua história como um momento singular da narrativa dramática e do gênero televisivo (BARRETO, 2014, p. 2)

Esta visão mais arrojada de serialidade pede dos estudiosos não que classifiquem as obras segundo certas categorias fixas ou as localizem em um dado ponto em um contínuo, mas que investiguem atentamente como cada série articula as dimensões do episódio, arco narrativo, temporada (quando a obra se segmenta em várias) e da série como um todo, movendo assim as dinâmicas de engendramento e singularização dos seus elementos narrativos. Este, aliás, é um 
dos principais problemas no modo como certos pesquisadores vêm se aproximando do conceito de complexidade narrativa (MITTELL, [2006]2012). Criado por Jason Mittell para lidar justamente com esta mescla contemporânea entre formas episódicas e continuadas, o conceito vem sendo empregado por muitos autores que aplicam o selo de "complexos" a certos seriados e assim se eximem de analisar as modulações internas específicas de serialidade nestas obras - de forma que, surpreendentemente, poucas abordagens analíticometodológicas não-classificatórias da serialidade foram de fato desenvolvidas nos estudos de televisão.

Neste artigo, buscamos trazer uma contribuição neste sentido, propondo um proto-modelo para a observação das narrativas continuadas de longo prazo em ficções seriadas televisivas - modelo este que foi desenvolvido em nossa dissertação de mestrado sobre Breaking Bad (ARAÚJO, 2015), seriado utilizado de modo ilustrativo neste trabalho. Após a apresentação do modelo proposto para a decomposição das narrativas continuadas em um produto televisivo, observamos alguns ganhos em relação a aspectos da obra que esta abordagem nos permite observar; nomeadamente no que diz respeito à modulação das temporadas, à economia eritmo narrativos e à convocação imersiva. Limitada em escopo, reconhecemos que no estágio em que se encontra, esta proposta de olhar sobre a serialidade não só ainda precisa ser testada em outros produtos, como também não dá conta da análise dos elementos episódicos de repetição e variação- e neste sentido ainda precisa de correções, avanços e melhorias. No entanto, os ganhos dessa mirada sobre a estrutura de longo prazo de uma obra seriada televisiva nos parecem suficientes para que sua publicação no estágio em que a proposta se encontra tenha mérito.

\section{Fios, tramas e tecido narrativo em Breaking Bad}

Para estabelecer um modo de decompor a narrativa longeva de uma série e hierarquizar suas personagens, recorremos aos conceitos de fio (thread), trama (braid) e tecido (fabric) narrativos. Conforme Wolf (2012, p. 199-201), um fio narrativo é uma estrutura criada por vários eventos ligados por vínculos causais que envolvem um grupo de atores num curso de ação. Wolf repara que, 
embora esta estrutura permaneça, diversos narratólogos propuseram modos distintos de analisar estes fios. Um dos esquemas mais usados neste sentido é o esquema actancial de Greimas (1976, p. 225-250), cuja utilidade no estudo de ficções televisivas já foi atestada por Balogh (2000, p. 58-65).

O esquema greimasiano é composto por seis atuantes divididos em três pares: sujeito e objeto (investimentos do querer), destinador e destinatário (investimentos do saber) e ajudante e oponente (investimentos do poder). Desta forma, um sujeito busca um objeto incitado pelo destinador, e quem se beneficia da busca do sujeito é o destinatário. Ele tem na sua busca apoio do ajudante e antagonismo do oponente. É importante notar ainda que os actantes greimasianos são estruturas, e não personagens. Isto não só implica que uma mesma personagem pode ocupar mais de um destes papéis, como também que estes papéis sequer precisam ser ocupados por indivíduos. Assim, as motivações que impulsionam um sujeito a buscar o objeto podem ser muito mais internas (auto manipulação) do que ligadas a um destinador externo, por exemplo. Neste esquema, a trajetória do sujeito desde a manipulação pelo destinador até o fim da busca pelo objeto é chamada de programa narrativo, e pode-se dizer que cada fio narrativo tem/é um destes programas.

Antes de aplicar o modelo greimasiano a Breaking Bad, no entanto, cabe fornecer alguns dados sobre o produto. Criado por Vince Gilligan e produzido por um consórcio entre a High Bridge Entertainment, a Gran Via Productions e a Sony Pictures Television, Breaking Bad teve suas cinco temporadas originalmente distribuídas entre 2008 e 2013 pelo canal a cabo americano AMC, que exibia a série aos domingos, às $21 \mathrm{~h}$.

A narrativa da série desenvolve-se mormente em uma versão ficcional da cidade de Albuquerque, Novo México, e acompanha a história de Walter White, um químico promissor, certificado como colaborador em projeto vencedor do prêmio Nobel de química², que acaba por se ver ministrando aulas no segundo

\footnotetext{
${ }^{2}$ De fato, a partir de uma pesquisa de Walter, ele e o amigo Elliott Schwartz, fundaram a empresa Gray Matter Technologies. Quando Walter sai da empresa, recebendo apenas 5 mil dólares, Elliott casa-se com a ex-assistente e ex-namorada de Walter, Gretchen, e o projeto desenvolvido pela empresa ganha o Nobel. A vida glamourosa do 
grau de uma escola da cidade. No episódio piloto, Walter descobre-se com câncer de pulmão e uma expectativa de vida de no máximo mais um ano. Ele então procura o seu ex-aluno Jesse Pinkman, um traficante de metanfetamina, e resolve usar seus conhecimentos como químico para fabricar o produto e entrar para o comércio de drogas; inicialmente, na esperança de deixar uma herança para a família após a sua eventual morte devido ao câncer.

Obstinado em produzir uma mercadoria de qualidade, ainda na primeira temporada, o protagonista desenvolve uma fórmula para fabricar metanfetamina cristal com um alto índice de pureza, que, por razões químicas, tem cor azulada, em contraste com o tradicional branco do produto. Sob o pseudônimo de Heisenberg, Walter logo atrai a atenção do departamento de combate às drogas da polícia federal americana, deixando seu insuspeito cunhado, Hank Schraeder, por acaso um agente federal, obcecado em descobrir quem é Heisenberg e em prender o criminoso.

Sob esse pseudônimo, Walter não tarda a desmantelar os negócios de seus concorrentes, se envolvendo com grandes agentes do tráfico - tanto os ligados a uma logística de distribuição pelo território americano, como o inconspícuo empresário de fast food Gustavo Fring, quanto os vinculados ao contrabando internacional, como os cartéis mexicanos ou as redes de transporte da droga para o leste europeu.

Até o fim da série, o protagonista deixa o tráfico e retorna a ele várias vezes, passa por problemas conjugais diversos e vai se tornando paulatinamente insensível às vítimas de seus crimes e a sua esposa Skyler, à medida que suas motivações cambiam, e deixar uma herança para a família passa a ser secundário frente à sua sede de poder.

Seguindo o modelo atuacional de Greimas, é possível identificar 13 distintos fios narrativos sustentados a longo prazo em Breaking Bad (Tabela 1). Longe de se isolarem, distintas associações entre estes fios constituem uma trama central e quatro secundárias na composição do tecido narrativo da série.

casal e o prêmio Nobel, do qual acredita-se mais do que mero colaborador, geram ressentimento por parte de Walter. 
Mas antes de observarmos estas tramas, é preciso que olhemos mais detidamente para os fios em si mesmos.

\begin{tabular}{|c|l|}
\hline $\begin{array}{c}\text { Ordem de } \\
\text { aparição }\end{array}$ & \multicolumn{1}{|c|}{ Situação } \\
\hline Fio 1 & $\begin{array}{l}\text { Vida do professor de química Walter White no tráfico após sua decisão de fabricar } \\
\text { drogas para deixar uma herança para a família antes de morrer. }\end{array}$ \\
\hline Fio 2 & Vida familiar do protagonista. \\
\hline Fio 3 & $\begin{array}{l}\text { As investigações de Hank (cunhado de Walter e agente federal) conectadas ao caso } \\
\text { Heisenberg (pseudônimo de Walter no mundo do tráfico, embora Hank a } \\
\text { princípio não saiba disso) e os impactos delas sobre a vida do agente. }\end{array}$ \\
\hline Fio 4 & $\begin{array}{l}\text { Descoberta por Skyler, esposa de Walter, da cleptomania da sua irmã Marie, } \\
\text { esposa de Hank, e modo como Skyler reage a essa descoberta. }\end{array}$ \\
\hline Fio 5 & $\begin{array}{l}\text { Saída de Jesse (ex-aluno de Walter e seu parceiro no tráfico) de casa, romance } \\
\text { com Jane (filha do dono da casa que passa a alugar) e retorno à antiga residência. }\end{array}$ \\
\hline Fio 6 & O caso extraconjugal entre Skyler e o seu chefe, Ted Beneke. \\
\hline Fio 7 & Vingança dos primos do traficante Tuco contra Hank, dado que o agente o matou. \\
\hline Fio 8 & Relacionamento entre Jesse e Andrea, a quem conhece no Narcóticos Anônimos. \\
\hline Fio 9 & Ciclo autodestrutivo de Jesse após cometer um assassinato. \\
\hline Fio 10 & A derrubada de um cartel mexicano pelo chefe do tráfico, Gustavo Fring. \\
\hline Fio 11 & $\begin{array}{l}\text { Tentativa de Skyler de evitar que seu ex-amante, Beneke, seja auditado pela } \\
\text { receita federal, por medo de que passem a investigá-la também (dado que ela era } \\
\text { contadora da empresa) e descubram os crimes do marido. }\end{array}$ \\
\hline Fio 12 & $\begin{array}{l}\text { Tentativa de Walter de lidar com as testemunhas deixadas para trás com a morte } \\
\text { de Gustavo Fring (antigo associado de Walter assassinado por ele e Jesse). }\end{array}$ \\
\hline Fio 13 & $\begin{array}{l}\text { Tentativa dos ex-sócios de Walter de continuar produzindo metanfetamina com a } \\
\text { mesma qualidade que o protagonista o fazia, após ele resolver deixar o tráfico. }\end{array}$ \\
\hline
\end{tabular}

Tabela 1: fios narrativos de Breaking Bad, na ordem em que se iniciam³.

O primeiro fio narrativo apresentado na série (fio 1) acompanha o ingresso do protagonista no narcotráfico e as desventuras que ocorrem a ele e Jesse enquanto transitam por ali - desde a decisão tomada por Walter de

3 O mapa actancial com os sujeitos, objetos, destinadores, destinatários, ajudantes e oponentes de cada um destes fios é extenso demais para ser anexado a este artigo, mas pode ser encontrado no Apêndice da nossa dissertação de mestrado (ARAÚJO, 2015, p. 154-166), disponível em: <https://www.academia.edu/26794263/Crystal_Blue _Persuasion_a_constru\%C3\%A7\%C3\%A30_do_mu ndo_ficcional_no_seriado_televisivo_Breaking_Bad>. Acesso em 30 ago. 2016. 
fabricar metanfetamina e do estabelecimento da parceria com Jesse (1x01) 4 até a morte do protagonista (5x16). Este fio narrativo tem Walter (sujeito) e Jesse (adjuvante e por vezes oponente) como seus actantes centrais. Ele é o primeiro apresentado no piloto - dado o fato de o episódio começar in media res, com uma sequência do protagonista dirigindo o trailer no qual a dupla fabrica a droga pelo deserto - e se estende até o series finale, quando Walter mata seus antigos associados neonazistas, liberta Jesse da escravização por estas personagens e morre. Os desenvolvimentos deste fio narrativo são muitos e lidam com os relacionamentos entre Walter e Jesse e um sem número de outros traficantes (Krazy 8, Tuco, Fring, os neonazistas, Lydia etc.). Aqui, o programa poético é associado mormente ao noir, com seu foco na vida criminal de personagens fora-da-lei.

O segundo fio (fio 2), único outro também iniciado no piloto, aborda outra dimensão da vida de Walter: a das as relações familiares - desde a apresentação do protagonista que, esperando o segundo filho, mal consegue arcar com as despesas da casa, até a despedida entre Walter e sua esposa no series finale, antes do protagonista partir para o confronto com a gangue de neonazistas, do qual só poderia sair encarcerado ou morto. Aqui, Walter e Skyler dividem o papel de actantes centrais com igual peso; e é justo afirmar que a partir de pontos de vista distintos qualquer dos dois pode ser colocado na posição de sujeito greimasiano. Nesse fio narrativo, o melodrama e o drama burguês parecem constituir o programa poético mais saliente, com sua ênfase na vida familiar e doméstica e nos estados internos, e a preferência em explorar variações relacionais entre um núcleo pequeno de personagens do que em trazer muitas personagens novas ao drama.

Apesar do critério de numeração dos fios entre 1 e 13 não ser hierárquico, e sim relativo à ordem na qual se iniciam na série, é notável que estes dois primeiros fios são os de maior importância para o tecido narrativo de Breaking Bad - afinal, eles não só são os únicos que se estendem do primeiro ao último

\footnotetext{
4 Neste artigo, utilizamos a abreviação número da temporada $\mathrm{x}$ número do episódio para identificar episódios específicos. Assim, 1xO1 equivale a "primeira temporada, primeiro episódio".
} 
episódio, mas também balizam a ambivalência do protagonista a partir do engajamento de Walter neles. Assim, é a interação entre estes dois fios que define a própria história do seriado como sendo sobre um homem de família que, ciente (aos cinquenta anos) da eminência de sua morte, decide entrar para o narcotráfico na expectativa de deixar uma herança para sua família, e a partir daí sofre progressiva decadência moral. Ademais, a partir da interação entre estes fios, a obra ganha um programa poético forte de drama criminal, como o que marca séries como The Sopranos: há um foco ao mesmo tempo na vida familiar e na vida criminosa de um protagonista fora-da-lei.

Por seu turno, o fio 3 é iniciado com a investigação de Hank sobre os desaparecimentos de Emilio e Krazy 8 (1xo3), cujos corpos se encontram no fundo do trailer que Walter dirige na primeira sequência; e finalizado com o assassinato do agente federal pelos neonazistas (5x14). Menos importante que os anteriores, este fio acompanha as investigações de Hank, os impactos de tais investigações sobre a vida pessoal desta personagem, e as tentativas que Walter empreende de sabotá-las. Nota-se que este fio narrativo é uma derivação do primeiro que ecoa no segundo, com as investigações de Hank comentando os crimes de Walter (fio 1) e o trabalho como agente do DEA impactando a vida familiar dele e a dos White (fio 2).

Este fio narrativo traz Hank, e não Walter, como principal actante. Mesmo assim, o protagonista ainda é um actante central aqui, não só orientando o objeto (a maior meta de Hank é descobrir quem está por trás do pseudônimo Heisenberg, usado por Walter) mas também sendo o oponente mais ativo (Walter sistematicamente sabota as investigações de Hank, e podem ser atribuídas a ele algumas das principais ações que impulsionam este fio narrativo). Em termos de programa poético, este fio traz ainda uma dimensão investigativa para a série, reforçando a influência do noir sobre ela, posto que acompanhamos tanto a investigação quanto os crimes, e que o investigador não está fisicamente seguro, elementos fundamentais no gênero (TODOROV, 2003). Mesmo sendo menos importante que os anteriores, este não deixa de ser o terceiro principal programa narrativo da série, se juntando aos fios 1 e 2 no conjunto daqueles que se estendem da primeira à última temporada. Se 
pensamos a interação entre os fios 1 e 3 e na ambientação específica da série, o western também aparece como um programa poético central, com sua ênfase no binômio lei/fora-da-lei, disputas de fronteira (do tráfico) e ambientação próxima ao deserto em uma contraparte ao sudoeste americano.

Os outros fios narrativos têm importância distinta entre eles, mas sempre menor que estes três. Seus programas poéticos, em geral, apresentam variações e ramificações dos previamente mencionados5. Aqui, cabe dizer que, além de ser entendidos como programas narrativos greimasianos, cada um destes fios pode ser também abordado como um arco de história. Isso porque em ficções seriadas, a estrutura (exposição - desenvolvimentos - clímax - desenlace) que compõe tais arcos não apenas se repete em cada episódio, mas também se verifica em cada uma das narrativas de longa duração. Se falamos em camadas ou níveis e pensamos a dimensão episódica como um primeiro nível, muitos destes fios podem ser encarados como arcos de segundo nível, por congregarem, em uma dimensão continuada, ações de distintos arcos episódicos. No entanto, estes três primeiros fios podem até mesmo ser considerados arcos de terceiro nível, pois são constituídos não só a partir da junção de vários arcos episódicos, mas também de vários arcos continuados menores.

Por exemplo: um arco continuado que tem início no piloto começa com a decisão de Walter de entrar para o tráfico e o estabelecimento da sua parceria com Jesse (exposição). A partir daí, a dupla fabrica metanfetamina e Jesse tenta repassá-la para o distribuidor local Krazy 8. Contudo, uma série de incidentes leva os dois a sequestrarem Krazy 8 e prendê-lo no porão de Jesse. Embora a dupla não tenha ímpeto assassino, Walter e Jesse sabem que, se liberto, Krazy 8 buscará vingança, e lidam com a difícil situação de ter que executá-lo (todos estes são desenvolvimentos). O clímax vem no terceiro episódio, quando Walter decide libertar Krazy 8, mas percebe que o jovem tem um caco de vidro em mãos e planeja matá-lo assim que for solto. Por fim, o assassinato de Krazy 8 e a decisão do protagonista de deixar o tráfico marcam o desenlace.

5 Descrições de cada um deles podem ser encontradas no Apêndice da nossa dissertação, conforme previamente mencionado na rodapé 3 . 
Todavia, pouco após a morte de Krazy 8, Walter decide buscar tratamento para o seu câncer, algo que ainda não estava certo de que iria fazer, e que implica em despesas altas - ainda mais dado que Walter se recusa a aceitar ajuda financeira. Além disso, o desejo que o protagonista tinha de deixar uma herança para a família após o seu eminente óbito não morreu junto com Krazy 8. Deste modo, Walter volta a procurar Jesse, e os dois decidem prosseguir fabricando a droga (1x04-1xo5, exposição). A partir daí, eles começam a trabalhar com o distribuidor local Tuco Salamanca, que substitui Krazy 8 (1x06). Após um conjunto de outros desenvolvimentos, o clímax se dá quando eles são sequestrados por Tuco, que pretende levar Walter para trabalhar num superlaboratório no México (2x01-2x02). O desenlace, por sua vez, é marcado pelo assassinato de Tuco por Hank (2xO2) e a volta do protagonista ao seio familiar (2xo3).

Os dois arcos descritos acima se conectam entre si, e então a um terceiro, quarto e assim por diante, compondo coletivamente o fio 1, que acompanha desenvolvimentos da vida de Walter no tráfico por toda a série; da decisão de fabricar a droga após descobrir o câncer (exposição), à publicização dos seus crimes e sua fuga (clímax), ao seu retorno a Albuquerque e sua morte (desenlace). Algo semelhante se passa com os fios 2 e 3, que, ao congregar vários arcos continuados menores (de segundo nível, articulando eventos de vários episódios), constituem em si mesmos arcos de maior longevidade (de terceiro nível, compostos por vários arcos pluriepisódicos). Aqui, é possível verificar mais uma vez a centralidade dos fios 1 e 2: eles não só são as únicos que duram do piloto ao series finale, mas também são compostos cada um por 13 arcos não-episódicos menores, enquanto o fio 3 (terceiro mais importante) é composto por apenas 7, e os fios 4 a 13 sequer chegam a estruturar um terceiro nível, sendo compostos cada qual por somente um arco continuado. 


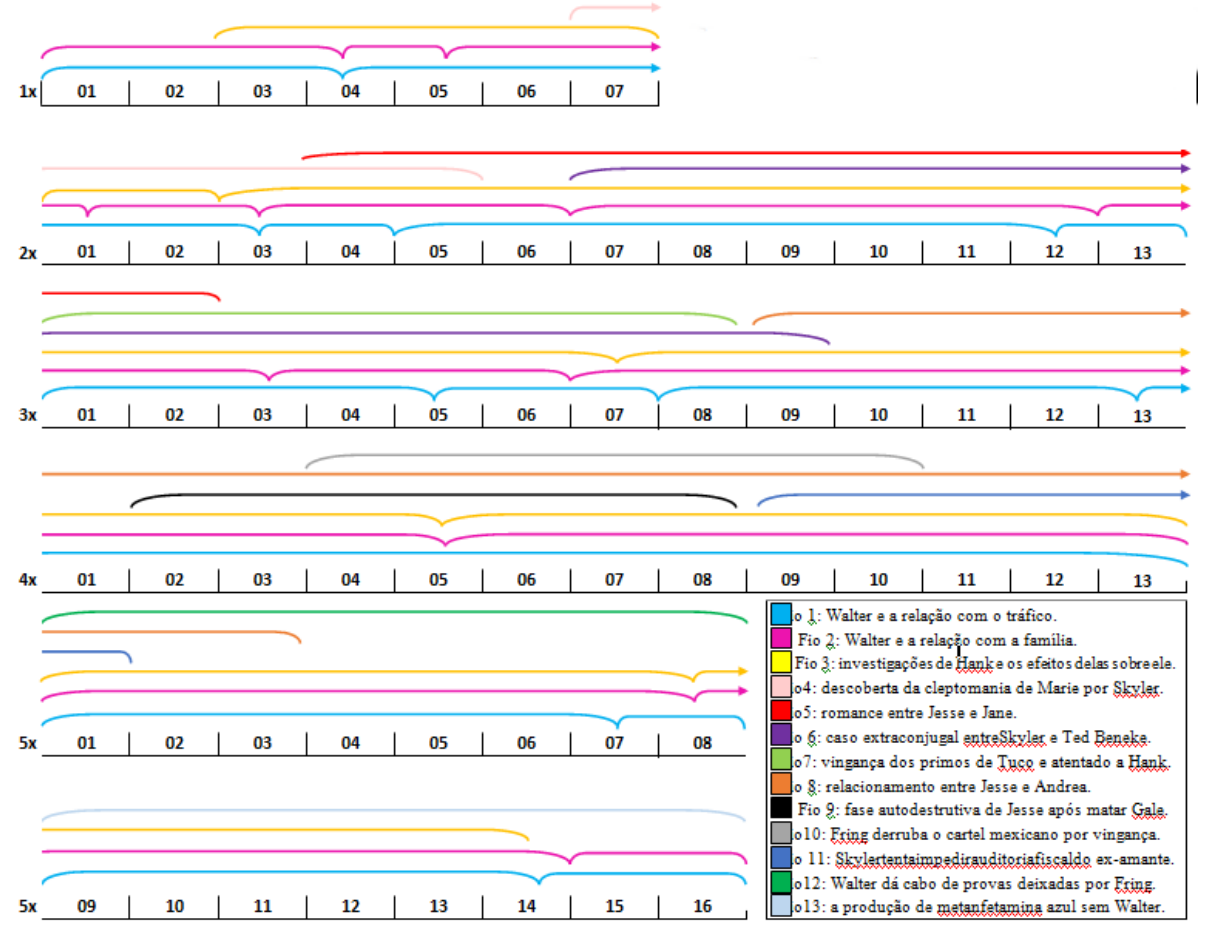

Figura 1: Fluxograma dos fios narrativos de BreakingBad. As flechas indicam prosseguimento do fio/arco na temporada seguinte.

As curvaturas apontam o episódio de início/fim do arco/fio, não o momento do episódio em que isso ocorre. Elas aparecem no meio da caixinha que

representa um episódio quando um novo arco do mesmo fio narrativo começa no mesmo episódio, e aparecem no fim da caixinha quando o novo arco só começa no próximo.

Mesmo que possam ter vários níveis de estruturação, é preciso deixar claro ainda que os fios narrativos não são as unidades composicionais máximas do enredo. Conforme Wolf (2012), dado que, em certas narrativas, fios diversos se desenvolvem concomitantemente e partilham os mesmos materiais diegéticos, tais fios podem se entrelaçar uns com os outros, compondo uma ou mais tramas que se organizam em torno de uma mesma personagem. Estas tramas podem ter ainda importância hierárquica variável para o tecido narrativo e, com frequência, uma delas se apresenta como principal e outras como secundárias. Ademais, um mesmo fio pode servir à sustentação de várias tramas, a partir de distintas teias de relações que venha a estabelecer com outros fios na estruturação global do tecido narrativo de uma obra.

A partir do exame actancial dos fios narrativos de Breaking Bad é possível chegar a quatro tramas, cada uma vinculada a uma personagem que figura como actante central em múltiplos fios narrativos. Certamente, a mais 
marcante destas tramas se configura em torno de Walter White. É fácil estabelecer a centralidade desta trama: ela é a única que conjuga os três fios narrativos mais importantes, posto que Walter é um actante crucial em cada um deles (nos dois primeiros ele é o sujeito e no terceiro um oponente bastante ativo). Além dos três fios principais, a esta trama se amarram também os fios 12 e 13, ambos ramificações do fio 1.

O fio 12 se desenvolve após a morte do grande chefe do tráfico, Gustavo Fring. Nele, Walter conta com a ajuda de Jesse e um antigo associado de Fring, chamado Mike, para pensar em uma forma de apagar o disco rígido do computador de Fring, que se encontra sob custódia policial e contém gravações em vídeo que podem incriminar os três. Além disso, o trio precisa ainda dar um jeito de manter caladas onze testemunhas capazes de identificá-los, todas vinculadas ao esquema de distribuição montado por Fring e presas após sua morte. Já o fio 13 acompanha um grupo de antigos sócios de Walter tentando manter a fabricação de metanfetamina azul sem o protagonista. Apesar dos sujeitos greimasianos deste fio serem estes antigos sócios (Lydia, Todd e os neonazistas), o fio serve não tanto para que acompanhemos a operação deles, mas para prover soluções para os fios narrativos principais, no que Walter se mostra um actante central ${ }^{6}$.

\begin{tabular}{|c|c|}
\hline Personagem seguida & Fios narrativos da Tabela 1 entretecidos em cada trama \\
\hline Walter (trama central) & Todos os principais fios narrativos $(1,2$ e 3 ), além dos fios 12 e 13. \\
\hline Jesse & Fios $1,5,8,9$ e 13. \\
\hline Skyler & Fios $2,4,6$ e 11. \\
\hline Hank & Fios 3 e 4. \\
\hline Fring & Alguns arcos do fio 1 , além dos fios 7 e 10. \\
\hline
\end{tabular}

Tabela 2: Tramas de Breaking Bad

Disputam o papel de trama secundária mais importante as que acompanham Jesse e Skyler, cada uma iniciada a partir de um dos dois principais fios da série, mas robustecida por um conjunto de outros programas narrativos. Quanto à trama que segue Jesse, ela começa acompanhando o rapaz

${ }^{6}$ É a interação de Walter com estes antigos sócios no fio 13 que leva à morte de Hank (fio 3) e à escravização de Jesse (fio 1), bem como à fuga do protagonista (fios 1 e 2). 
enquanto parceiro de Walter no crime (fio 1), mas depois entretece fios relacionados aos casos amorosos do jovem com Jane (fio 5) e Andrea (fio 8), à sua fase autodestrutiva após cometer assassinato pela primeira vez (fio 9) e à sua eventual escravização por neonazistas (fio 13), além de dramas episódicos vinculados a seus pais ou amigos.

Por sua vez, a trama que segue Skyler começa acompanhando a personagem a partir da vida conjugal e doméstica (fio 2). Uma situação familiar específica logo ramifica outro fio narrativo (fio 4), relacionado à descoberta da cleptomania da sua irmã Marie (esposa de Hank) por Skyler e aos modos como a personagem resolve lidar com isso. Mais tarde, a trama se expande para além da família, quando envereda pela exploração narrativa do caso extraconjugal que Skyler inicia com Ted Beneke (seu chefe, com quem já tinha uma relação ambígua), o que se dá num momento em que Walter volta para casa contra a vontade dela, após Skyler ter decidido se separar do marido (fio 6). Aqui, Skyler se configura como cúmplice numa fraude fiscal cometida por Beneke, e mais tarde ela precisa evitar que a receita federal audite a empresa de Ted, pois mesmo os dois não sendo mais amantes, a auditoria poderia levar Skylar a ser investigada, o que por sua vez inevitavelmente traria à tona os crimes do marido (fio 11).

A terceira mais importante trama secundária segue as investigações de Hank (fio 3), bem como a mediação que ele tenta estabelecer na rusga entre Skyler e Marie (fio 4). Já a menos importante das tramas secundárias acompanha Gustavo Fring, inicialmente enquanto associado de Walter no universo do tráfico (alguns arcos do fio 1), mas depois seguindo as desavenças entre Fring e um cartel mexicano. Estas desavenças começam a se fazer visíveis quando, após o assassinato do traficante Tuco Salamanca por Hank, dois primos de Tuco vêm do México para vingá-lo. Como Hank é policial, portanto intocável, a vingança é centrada em Walter, que também foi fundamental na morte de Tuco, conforme os primos descobrem. Almejando tornar Walter seu funcionário, Fring deseja frustrar os planos de vingança dos rapazes. "Dono" do território do sudoeste americano, Fring proíbe o assassinato de Walter, mas autoriza que os irmãos matem Hank, mesmo ele sendo agente federal. No 
entanto, Fring telefona para Hank pouco antes do atentado, possibilitando que a personagem escape da morte e consiga, ao invés, matar um dos irmãos. O irmão que sobrevive é assassinado pelo próprio Fring no episódio seguinte (fio 7). Posteriormente, nos é revelado que o ódio de Fring pelos membros cartel é histórico, posto que eles mataram o seu parceiro, Maximino Arciniega. Assim, podemos suspeitar que as razões de Fring para matar os irmãos eram maiores do que a vontade de empregar Walter, e se deviam a tais desavenças históricas. Então, acompanhamos quando Fring desmantela o cartel para vingar o seu parceiro (fio 10).

Por fim, uma vez explicitado, por meio da análise de Breaking Bad, o modelo que estamos propondo para a decomposição da estrutura continuada de seriados televisivos a partir do esquema actancial greimasiano e dos conceitos de fio, trama e tecido narrativo, exploramos no próximo tópico algumas vantagens desta mirada. Neste sentido, nossa aposta é que a partir da decomposição dos fios narrativos, o analista pode observar: 1) as modulações das temporadas, 2) a economia narrativa em termos de quanto a série se concentra em poucos acontecimentos e linhas de ação ou se espalha por diversos deles, 3) os modos de convocação imersiva da obra, 4) o ritmo da narrativa, e 5) o quanto a série multiplica suas tramas ou se concentra em um número pequeno delas. Isso para além da observação de que fios narrativos se associam a que matrizes genéricas, algo que destrinchamos na própria exposição dos fios quando falamos no noir (fio 1), no melodrama (fio 2), no drama investigativo (fio 3), no drama criminal (interação entre o fio 1 e 2) e no western (fios 1 e 3).

\section{As vantagens desta abordagem}

Um dos primeiros elementos que a decomposição dos fios narrativos nos permite observar é a modulação das temporadas. No caso de Breaking Bad, a observação da Figura 1 permite perceber que, da primeira à terceira delas, os arcos narrativos raramente se concluem ao fim da temporada, quase sempre se encerrando alguns episódios antes do seu fim ou alguns episódios após o início da próxima, deixando ganchos a serem resolvidos e fios narrativos em 
suspensão entre uma temporada e outra. Uma decomposição semelhante em séries como 24 ou Buffy the Vampire Slayer, por sua vez, provavelmente mostrariam um claro encerramento da maioria dos arcos ao fim de cada temporada, com no máximo um ou dois deles se estendendo para as próximas. De certa forma, Breaking Bad faz isso nos seus últimos três anos de exibição, e a quarta e as duas metades da quinta temporadas são muito mais conclusivas em seus arcos, mostrando um câmbio no modo como a série lida com a serialização no nível da temporada.

Já no que diz respeito ao nível de condensação ou espraiamento narrativo de uma série, a concentração do tecido narrativo de Breaking Bad se torna claramente visível a partir da observação de como os fios narrativos 1, 2 e 3 interagem entre si: são numerosos os eventos que impactam a um só tempo as incursões de Walter e Jesse no tráfico, a vida familiar do protagonista junto a Skyler,e as investigações de Hank, em especial sobre crimes relacionados a Heisenberg. Dada a existência de múltiplos eventos importantes que entrecruzam e refiguram estes três fios narrativos (os mais importantes e longevos), longe de dispersar o enredo e forçar o apreciador a excursionar por três caminhos distintos, o desenvolvimento paralelo destes três fios e das tramas a eles associadas reitera junto ao público a importância das ocorrências e personagens ligadas a tais fios e tramas, tornando-as memoráveis e facilitando a imersão.

Por exemplo, em dado momento, o traficante Tuco Salamanca espanca um de seus comparsas até a morte (1x07). Quando os corpos deste e de outro traficante são encontrados pelo DEA, Tuco se torna um foragido (2xo1). Ele então sequestra Walter e Jesse (2x01-2x02), o que faz porque pretende fugir para o México e deseja levar o protagonista consigo para que Walter trabalhe em um superlaboratório de produção de metanfetamina (fio 1). Neste período, a família White fica desesperada com o sumiço do patriarca, e espalha cartazes pela cidade na tentativa de encontrá-lo, com a ajuda de Marie, irmã da esposa do protagonista (fio 2). Hank, por sua vez, divide seu tempo investigando simultaneamente o desaparecimento de Tuco no trabalho junto à polícia federal e o sumiço de Walter como um favor à família (fio 3). Verifica-se aqui que um 
mesmo evento, o sequestro do protagonista e de Pinkman por Tuco, rearranja os três principais fios narrativos. Este evento - que impacta profundamente as vidas de Walter, Skyler, Jesse e Hank (e portanto é importante para quatro das cinco tramas) - tem assim sua centralidade redundada ao público, facilitando a sua memorização e possibilitando que ele seja referenciado repetidamente em episódios subsequentes sem que o espectador precise dar um passo atrás na experiência imersiva para recordar tal acontecimento.

Em outro momento, quando as tensões entre Walter e o traficante Gustavo Fring escalam, o distribuidor só não mata o protagonista porque vem se aproximando de Jesse, que diz a Fring que não trabalhará mais para ele caso Walter morra. Gustavo então leva Walter ao deserto e lhe dá a oportunidade de deixar de vez o tráfico e continuar vivo (4x11), mas o protagonista zomba da sua proposta e diz saber que Fring está com as mãos atadas. Afinal, o distribuidor não poderia matá-lo sem criar uma desavença com Jesse, a última coisa que Fring desejaria, dado que Pinkman é a única pessoa viva, além de Walter, capaz fabricar a metanfetamina azul.

Então, impressionado com a insolência de Walter, Fring diz que até pode estar impossibilitado de matá-lo, mas que nada o impede de executar toda a sua família, a começar por Hank, uma vez que o investigador vem lhe causando problemas. Através desta ameaça, Fring finalmente consegue o efeito desejado no protagonista, que deixa o local desesperado. A primeira providência de Walter após o encontro é pedir que o advogado Saul Goodman faça uma ligação anônima e avise a polícia da ameaça ao cunhado, e o advogado atende ao pedido. Logo após falar com Goodman, Walter explica a Skyler que eles precisam fugir e providenciar novasidentidades. Todavia, eles acabam sem poder tomar este exato curso de ação, pois Skyler já havia gastado boa parte dos recursos que o marido conseguira com o tráfico para ajudar seu chefe e examante, Ted Beneke, a não ser investigado por fraude.

Deste modo, outra solução precisa ser pensada para lidar com Fring. Enquanto isso não acontece, Skyler e os filhos se deslocam para a casa de Hank e Marie (4x12), guardada pela própria polícia federal por conta do telefonema de 
Goodman denunciando uma ameaça à vida do agente. Isto é, temos Skyler - que não pode partilhar com ninguém da família sua apreensão pelos riscos que corre Walter - presa na casa de Hank (fio 2), que vem investigando Fring (fio 3), a quem Walter tenta matar antes que algum membro da sua família seja executado (fio 1). Novamente, um mesmo evento (desta vez a ameaça feita por Fring à família de Walter) repercute nos três fios, rearranjando todos eles, tornando o evento em si mais recordável e a imersão mais fácil nos episódios seguintes, quando tal evento é referenciado e demanda-se que o público tenha ciência dele. Mais uma vez, o impacto sobre o tecido narrativo é amplo, posto que as vidas de Skyler, Walter e Hank são marcadas por esta ocorrência.

A decomposição do tecido narrativo em fios e tramas nos permite, assim, averiguar a economia narrativa a partir do exame do quanto os fios e tramas se tocam e partilham eventos (condensando o enredo, como no caso de Breaking $B a d$ ), ou inversamente quão isolados eles são em um dado seriado. Quer a narrativa se espalhe a partir de múltiplos eventos que não se tocam ou concentre em torno de muitos acontecimentos partilhados, os eventos comuns a múltiplos fios narrativos e tramas sem dúvida merecem uma observação mais detida em termos de análise do enredo de longo prazo, e podem dar fortes indicativos inclusive de variações na economia narrativa. No caso de Breaking Bad, por exemplo, a partir da segunda metade da quinta temporada, a conjunção dos três principais fios narrativos - e das quatro tramas marcadas por eles - fica mais forte do que nunca, de forma que entre os episódios nove e quatorze quase todos os eventos importantes são partilhados a partir de uma hiperconexão dos três fios centrais: após ser descoberto pelo cunhado, Walter tenta fazer Hank desistir de provar que ele está de fato envolvido com o tráfico e ao mesmo tempo toma medidas para eliminar as provas deste envolvimento, mas não conta com o fato de Jesse eventualmente se dispor a ajudar Hank (fio 1); Skyler encontra-se decidida a permanecer ao lado do marido e alienada da irmã e do cunhado, agora cientes da sua carreira ilegal (fio 2); e Hank tenta provar que Walter é um criminoso e convencer Skyler e Jesse a ajudá-lo (fio 3).

Ou seja: a descoberta por Hank de que Walter está envolvido com o tráfico de drogas, a busca de Walter por ocultar todas as provas de seus crimes 
enquanto Hank tenta prová-los, a opção de Skyler em apoiar o marido e não ajudar Hank, a insistência (e eventual convencimento) de Hank para que Jesse o ajude...Enfim, a maioria dos eventos importantes da segunda metade da quinta temporada opera conjunções entre estes três fios através do entrecruzamento dos cursos de ação das personagens. Mais uma vez, estas conjunções tornam tais eventos mais memoráveis, as referências a eles mais sólidas junto ao apreciador e a imersão mais fácil, e provavelmente se tornam ainda mais fortes por conta da série caminhar para o fim.

Ademais, como estes três fios compõem juntos o grosso da trama central e cada um deles sustenta de modo independente uma das principais tramas secundárias ao longo da obra, a conjunção entre estes três fios mantém as tramas secundárias próximas à central, com vários acontecimentos partilhados e constantes referências cruzadas a tais acontecimentos, o que implica num fortalecimento da grande economia narrativa da série.

Ao nosso ver, no caso de Breaking Bad, a imersão é facilitada por essa estruturação dos três fios mais longevos porque os eventos centrais do enredo de fato reconfiguram a teia de relações das personagens, concentrando as tramas ao preferir referências múltiplas aos mesmos eventos ao invés de multiplicar os eventos em si. Isso não só reforça a credibilidade do tecido narrativo, como também lembra ao espectador as ocorrências do passado recente, permitindo que ele trafegue por aquele mundo com tranquilidade em episódios que se sucedem, sem que precise quebrar a imersão com frequência para recordar uma personagem ou lembrar como os protagonistas se envolveram em uma situação. Certamente, a decomposição dos tecidos narrativos de outros produtos seriados pode igualmente deixar ver outros modos de convocação imersiva, e a análise dos próprios modos de engajamento imersivo proporcionados pela série pode se beneficiar de uma decomposição do seu tecido narrativo, para além das questões relativas à estrutura das temporadas e à economia narrativa.

Aliás, ainda em termos de economia narrativa, pode-se reparar que o total de fios narrativos é por si só reduzido em Breaking Bad. Para além dos fios 
1, 2 e 3, que seguem do início ao fim da série, em nenhum momento mais de três outros são narrados ao mesmo tempo, e o total de fios narrativos acessórios se desenvolvendo em simultâneo nunca ultrapassa o total de fios mais importantes (Figura 1). Essa economia pode causar uma impressão de que a narrativa se desenvolve lentamente, e no caso de Breaking Bad isso é perceptível pelo próprio fato de que os arcos dos principais fios narrativos vão ficando mais longos (durando mais episódios) no curso da série, mostrando que o ritmo da obra se desacelera progressivamente.

Esta progressão na desaceleração do ritmo pode ser acompanhada tanto na narrativa quanto na montagem. Narrativamente, embora os tamanhos dos arcos de cada um dos três principais fios narrativos da trama central variem, a linha de tendência nos três casos é crescente, mostrando uma disposição geral de arcos cada vez mais demorados em cada um destes fios (Figura 2). O ritmo da montagem, por sua vez, também se torna paulatinamente mais lento, e as variações na duração média do plano em cada episódio indicam tomadas cada vez mais longas (Figura 3). Desta forma, se no piloto os planos duram em média 4,6 segundos - dentro do que é típico em séries americanas, que segundo Butler (2010, p. 9-10) é a variação de 3 a 5 segundos -, no series finale, o plano médio dura quase o dobro disso ( 8,4 segundos).

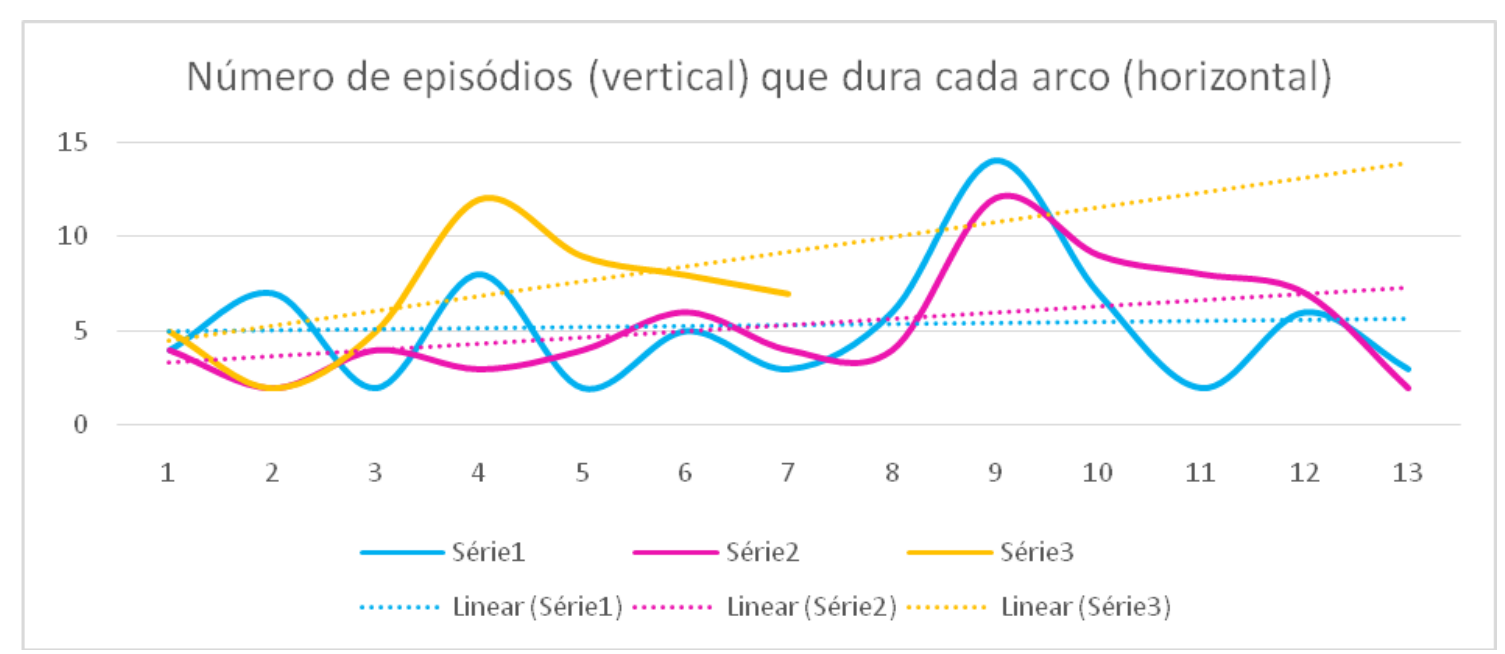

Figura 2: Ritmo dos fios narrativos principais. Cada série corresponde a um fio. Os lineares apresentam a linha de tendência para cada fio. A inclinação é mais leve nos casos dos fios 1 e 2, além de indicar que eles se desenvolvem em ritmo razoavelmente parecido no meio da série, apesar das variações no início e no fim. O fio 3 , no entanto, se torna muito mais lento, muito mais rápido. Ele acaba antes dos outros por só ter 7 arcos. 


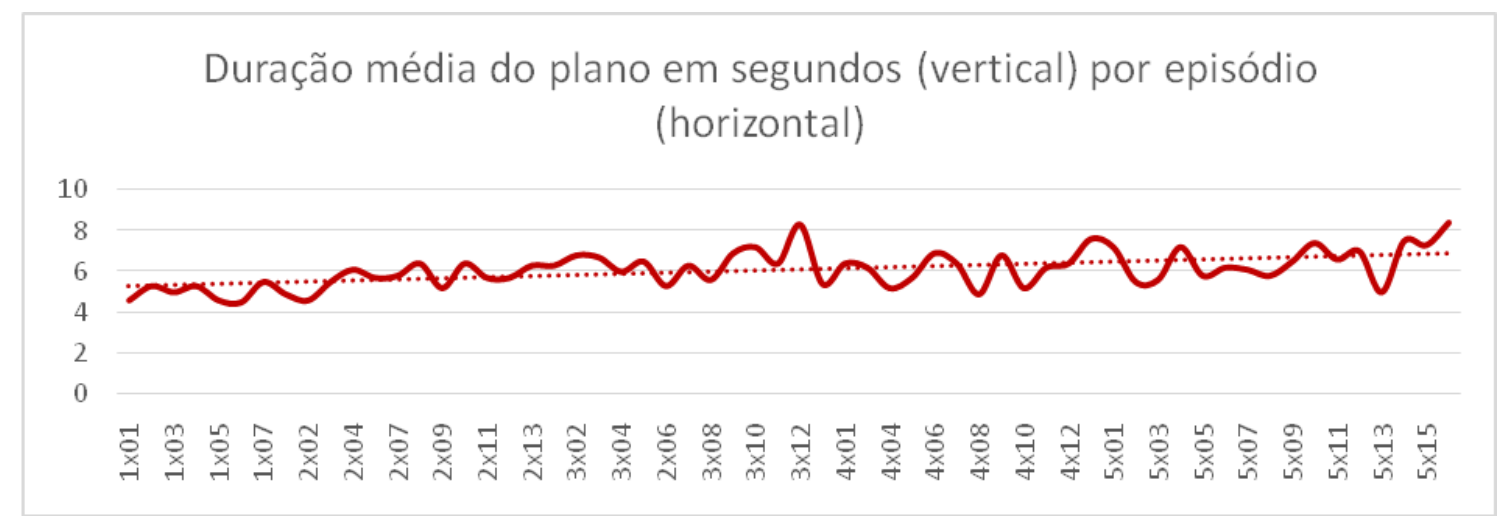

Figura 3: ritmo da montagem. Os dados foram obtidos pelo pesquisador Adrián Tomás Samit, mestre em Estudios de Cine y Audiovisual Contemporáneos pela Universitat Pompeu Fabra, e postados na base dedados colaborativa Cinemetrics <http://www.cinemetrics.lv/ >, projeto encabeçado por Bary Salt, e cuja fiabilidade já foi atestada por autores como Bordwell (2008). Apesar do gráfico não mostrar a numeração de cada episódio no eixo horizontal por questão de espaço, ele foi gerado a partir de dados de quase todos os episódios (60), faltando apenas 2 (2xo6 e 4x03), que não foram decupados por Samit. Todavia, a ausência deles não é suficiente para afetar a linha de tendência, que parece próxima a um meio termo entre as geradas pelos fios 1 e 2 no gráfico anterior.

Essa concentração narrativa e lentificação dos arcos em Breaking Bad permanece intacta mesmo quando observamos as tramas secundárias, o que ocorre devido a fatores como o fato de que tais tramas são em número reduzido (quatro no total, apenas três das quais se estendem por cinco temporadas). Além disso, nota-se que os próprios fios 4 a 11, através dos quais as tramas secundárias se ampliam, se entrelaçam em vários pontos com a trama central na costura do tecido narrativo de Breaking Bad, o que demonstra um esforço por direcionar o espectador para a narrativa principal e eventos cruciais para ela.

Por exemplo, o caso que Skyler mantém com Beneke (fio 6), a partir do qual a trama da personagem é ampliada para além do círculo familiar, é sem dúvida impulsionado por eventos do fio 2. É só por conta de Skyler sentir-se sequestrada por Walter, num momento em que ele volta para casa à revelia da esposa após ter sido expulso, que ela dá início ao seu caso extraconjugal - ainda que a relação entre ela e Ted já fosse ambígua. Do mesmo modo, o fato de Skyler usar quase todo o dinheiro guardado por Walter para que Beneke evite problemas com a receita federal (fio 11) reconfigura no fio 1 a maneira como a ameaça de Fring precisa ser enfrentada pelo protagonista, incapacitado de fazer uso do dinheiro para providenciar novas identidades para a família e fugir. Ainda no seio familiar, mesmo a descoberta da cleptomania de Marie por Skyler 
(fio 4) serve acima de tudo para gerar um afastamento entre as irmãs, isolando afetivamente Skyler justamente no momento em que a família White (fio 2) está abalada, inicialmente pelo desaparecimento e depois pelas mentiras de Walter. Isso reforça mais uma vez o fato de haver em Breaking Bad um tecido narrativo altamente concentrado, com as já mencionadas consequências disso para o ritmo e a convocação imersiva.

\section{Considerações finais}

A serialidade é um dos temas mais caros aos estudos de televisão desde a origem do campo, tendo dado vasão ao surgimento de um conjunto de modelos dedicados à sua abordagem. Inicialmente binários e a partir dos anos 1980 concentrados em tipologias multíplices, estes modelos de exame da serialidade quase sempre foram classificatórios e redutores, e só nos anos 2000 começaram a surgir miradas não taxonômicas sobre o tema. Ainda assim, mesmo contemporaneamente, a maioria das investidas que pensam a serialidade seguem ignorando as modulações tanto episódicas quanto de longo prazo em cada obra, ora localizando as séries num contínuo que planifica estas duas dimensões, ora adjetivando as séries como "complexas" e assim se livrando de realmente se debruçar sobre elas.

Neste artigo, buscamos nos distanciar destas perspectivas e apresentar uma proposta de decomposição da estrutura narrativa de longo prazo de um seriado a partir dos conceitos de fio, trama e tecido narrativos e do modelo actancial greimasiano, que argumentamos trazer em seu bojo as vantagens de nos permitir perceber: as distintas modulações da serialidade ao longo das temporadas (e, assim, não ignorar que o grau de continuidade de um produto televisivo pode mudar entre uma temporada e outra); a economia narrativa relacionada tanto à multiplicação ou concentração dos fios e tramas quanto à partilha maior ou menor de eventos entre elas;o ritmo narrativo; e mesmo as estratégias de convocação imersiva.

Reconhecemos que, neste sentido, ainda há muito trabalho a ser feito, razão pela qual evitamos chamar esta abordagem de método, ainda que ela aponte caminhos metodológicos. Neste sentido, é preciso antes de tudo testar o 
modelo com o exame de outros produtos com graus variados de continuidade, notando como a abordagem se sustenta na interface com obras cuja serialização é claramente vinculada a questões de dia da semana (a exemplo de Justiça ou Sessão de Terapia) ou temporada (como American Horror Story). Ademais, para dar conta dos modos de serialização contemporâneos também é preciso que o modelo apresentado seja organicamente articulado a outro que permita observar as dimensões episódicas de uma obra, e que seja desenvolvido um modo de observar a interface entre o episódico e o continuado.

Ainda assim, cremos que o trabalho representa um importante avanço no que concerne a abordagens não binárias ou taxonômicas da serialidade, apresentando uma mirada sensível às especificidades de cada produto, dando um pequeno passo metodológico no que concerne às possibilidades de exame das narrativas de longo prazo em produções seriadas.

\section{Referências}

ALLRATH, Gaby; GYMNICH, Marion; SURKAMP, Carola. Introduction: towards a narratology of TV series. In: ALLRATH, Gaby; GYMNICH, Marion (Eds.). Narrative strategies in television series. Hampshire: Palgrave Macmillan, 2005, p. 1-43.

ARAÚJO, João. Crystal Blue Persuasion: a construção no mundo ficcional no seriado televisivo Breaking Bad, 2015, 167f. Dissertação (Mestrado em Comunicação e Cultura Contemporâneas) - Faculdade de Comunicação, Universidade Federal da Bahia. Salvador, 2015.

BALOGH, Anna. O discurso ficcional na tevê. São Paulo: EdUSP, 2000.

BARRETO, Marcel. Origem do drama seriado contemporâneo. In: ENCONTRO ANUAL DA COMPÓS, 23., 2014, Belém. Anais Eletrônicos... Belém: UFPA, 2014. Disponível em: <http://compos.org.br/encontro2014/anais/Docs/GT12_ESTUDOS_DE_ TELEVISAO/compo_s2014final-corrigido_2245.pdf>. Acesso em: 1 jun. 2014.

BORDWELL, David. Rio Jim, in discrete fragments. [s.l.]: David Bordwell's website on cinema, 2008. Disponível em: $<$ http://www.davidbordwell.net/blog/2008/07/21/rio-jim-in-discretefragments/>. Acesso em: 9 dez. 2014.

BUTLER, Jeremy. Television style. New York: Routledge, 2010.

CALABRESE, Omar. La era neobarroca. Madrid: Cátedra, 1999. 
ECO, Umberto. Sobre os espelhos e outros ensaios. Rio de Janeiro: Nova Fronteira, 1989.

FEUER, Jane. Genre study and television. In: ALLEN, Robert. (Org.). Channels of discourse, reassembled: television and contemporary criticism. 2. ed. London: Routledge, 1992, p. 104-120.

GREIMAS, A. J. Semântica Estrutural. 2. ed. São Paulo: Cultrix, 1976.

MITTELL, Jason. Complexidade narrativa na televisão americana contemporânea. Matrizes, São Paulo, v. 5, n. 2, p. 29-52, 2012.

TODOROV. Tipologia do romance policial. In: Poética da Prosa. São Paulo: Martins Fontes, 2003, p. 63-77.

VILCHES, Lorenzo. "Play it again, Sam". Anàlisi, Barcelona, v. 1, n. 9, p. 5770 , 1984 . Disponível em: <http://www.raco.cat/index.php/Analisi/article/view/41268/88272>. Acesso em: 24 fev. 2012.

WOLF, Mark. Building imaginary worlds: the theory and history of subcreation. New York: Routledge, 2012. 